\title{
SAFETY INTEGRATED WITH QUALITY MANAGEMENT AS OPERATIONAL EXCELLENCE TOOL IN THE AVIATION FUEL INDUSTRY
}

\author{
Aderibigbe Israel Adekitan*
}

Department of Electrical and Information Engineering, College of Engineering, Covenant University, Ogun, Nigeria

\begin{tabular}{l}
\hline ARTICLE INFO \\
\hline Article history: \\
Received: 30.4 .2018$. \\
Received in revised form: 2.7 .2018$. \\
Accepted: 4.9 .2018$. \\
\hline Keywords: \\
jet $A-1$ aviation fuel \\
risk assessment \\
safety and quality management systems \\
safeguards \\
process safety management \\
aircraft accidents \\
\hline DOI: http://doi.org/10.30765/er.40.3.02
\end{tabular}

\section{Introduction}

Fuels are vital for transportation [1], and jet fuel is a major resource for the aviation fuel industry, accounting for about $40 \%$ of the total operational cost of some airline which makes it a major business cost component. According to the study by [2], jet fuel is one of the major factors that affects flight safety $[3,4]$; with the quality of jet fuel being the major issue. This makes it imperative to ensure that the jet fuel supply value chain is fortified with adequate safety and quality systems, guidelines and practices that will guarantee the supply of on-spec jet fuel for aviation purposes [5]. According to [6], The ISQMS

\begin{abstract}
:
Factors such as aircraft design, air traffic control, aviation fuel quality, management policies, etc. are associated with flight safety. Diverse methodologies and systems have been developed for managing these intricate factors. Much focus over time has been on the aircraft itself; the design, pre-flight checks and operational procedures. This study is focused on highlighting how the combination of Safety Management Systems (SMS) and Quality Management Systems $(Q M S)$ are deployed in the jet fuel value chain for ensuring the safety of personnel, the integrity of the work process and facility and ultimately the supply of quality and dry on-spec Jet A-1 fuel for into-plane or fuelling operations. For the integrated safety and quality management system (ISQMS) to be effective, all stakeholders must play active roles and show utmost commitment to the ISQMS vision and goals. The management of the fuelling company sets the ISQMS pace and drives the process. The ISQMS incorporates all aspect of the business operations and offers both direct and indirect benefits to the business.
\end{abstract}

encompasses Total Safety Management [7, 8] and Total Quality Management (TQM) [9]. TSM and TQM are proactive methodologies that transcend beyond the traditional approach to safety and quality management $[8,10]$; both methodologies ensure active participation of all stakeholders, performance status monitoring and continuous improvement with considerations for long term safety and quality goals. Aviation fuel quality has been associated with a number of aircraft mishaps [11], preventing fuel related aircraft accidents calls for the implementation of purpose specific industry safety guidelines to ensure personnel safety and jet fuel quality. Safeguards and safety management systems are deployed starting

\footnotetext{
* Corresponding author

E-mail address: ade_kitan@yahoo.com
} 
from the refinery where jet fuel is produced at the right specification and quality, up to the point of transportation via pipelines and rail tanks or export via ships till it arrives at the Intermediate Shore Depot. Here is where the product is discharged, and later transported to airfield depots as the final storage point before it is supplied to air tarmac via refuellers or hydrant systems for aircraft refuelling purposes. All through these stages, the integrity of the fuel must be maintained to prevent contamination by water, particles, microbes, surfactants, etc. which can degrade the quality of the fuel and impact negatively on the aircraft fuel system and engine.

According to the International Air Transport Association (IATA), Safety Management System (SMS) is a systematic approach to managing safety, including the necessary organizational structures, accountabilities, facilities, policies and procedures put in place to ensure that the business objectives are met safely. SMS was deployed in the construction industry in the early 80 s to reduce safety risk, prevent hazardous conditions and to cut down material wastage [12]. SMS ensures that safety is maintained at an acceptable level all through the process or facility life span [13]. The aviation fuel industry requires optimum safety in all aspect of its operation. SMS is for managing the risks in the aviation fuel companies to ensure the protection of lives, assets and reputation by ensuring that all activities are subject to the best of control and process scrutiny.

To ensure optimum safety, operational safety must be approached holistically by ensuring that every aspect of the operation is duly assessed for risks and identified risk are adequately mitigated. Standalone safety programs that addresses only an aspect of the larger safety puzzle are grossly inadequate [14]. SMS encompasses all aspects of the operation and it engages all stakeholders - management, employees and contractors. The study by [15] shows that irrespective of management's effort on safety, the workforce must be actively involved in the process for it to be effective. SMS sets measurable expectations [16] and duties for each stakeholder towards achieving safety; the ultimate goal.

The focus of safety management system has evolved overtime towards a sustainable improvement of key performance metrics as shown in the trend analysis of figure 1, SMS is structured to address risk at work, and it covers every aspect of the organization; technical, human or otherwise.

SMS is more popularly known in air transportation, with a focus on eliminating aircraft accident by ensuring adequate risk assessment, and management of factors that affects aviation safety such as the environment, maintenance, air traffic control, operations, management, etc. The effectiveness of SMS is often measured quantitatively via a safety index or safety performance indicators [7, 16-19]. The post SMS implementation study by [20] using structural equation modelling shows that SMS has several positive effects not just on the overall organizational safety but also on the competitiveness and the economic performance of the organization due to the improved image of the organization, and as such SMS is not an economic burden on organizations but rather an advantageous opportunity. The quantitative and qualitative study by [18], established the feasibility of implementing integrated SMS for small scale establishments, this confirms the scalability of SMS.

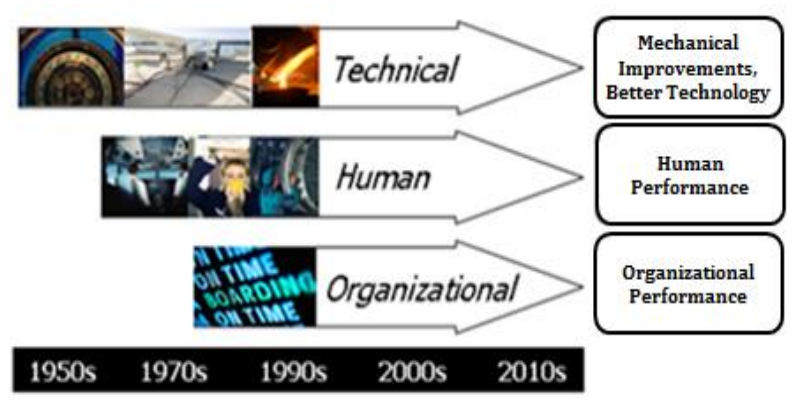

Figure 1. Evolution of safety thinking (Source: Federal Aviation Administration)

In the nuclear industry, the scope of SMS covers organizational issues, regulatory issues, employee issues, management issues, technological issues, etc. This is to ensure full scale facility and system integrity, and to promote top-notch safety consciousness among all stakeholders. In deploying SMS, preferences in methodologies do exist among countries as some tends towards behavioural sciences while others opt for quality management system in their efforts to elevate safety performance [13].

This study highlights the SMS and QMS deployed along the jet fuel value chain to ensure process and operations integrity, protect personnel and also ensure the dispensing of quality, dry, contamination free and on-spec jet fuel into aircraft. Ensuring safety of people and process at all times in aviation fuel operations is achieved by putting in place structures and systems to prevent errors, and also ensure compliance with regulations and procedures. 


\section{Components of SMS and QMS along the Jet Fuel Value Chain}

The integrated SMS and QMS are aimed specifically at achieving on-spec jet fuel supply for into-plane operations. This study will highlight the role of various components of ISQMS along the jet fuel value chain.

According to the US Federal Aviation Administration as detailed in FAA Order 8000.369, and in Doc 9859 - AN/474 Safety Management Manual by the International Civil Aviation Organization, SMS has four basic elements and these are safety policy, safety risk management, safety assurance, and safety promotion. For SMS to achieve its goals, it must be developed on these four building blocks, involve all stakeholder, must be proactive and performance oriented. Setting up SMS and QMS requires that the business performs a self-study of its operations and critical decisions around the operation. Expert review and risk assessment of process activities must be performed to identify threats and to develop effective mitigations. The Management is the core driver of SMS and QMS in any establishment, and must select the appropriate team with the relevant experience and skills to run the ISQMS. The success of ISQMS in industries is largely a function of management's demonstrated commitment [12, 21]. To achieve safety, management's effort must go beyond paper work to full implementation of safety policies and guidelines [22]. Management sets the pace by goal setting (mission, vision, safety objectives etc.), planning and development of policies, determining implementation strategies and ensuring progress review and improvements. The ISQMS process is detailed and covers key aspects of the operation as shown by the overview diagram of Figure 2 . The risk assessment and hazard identification are critical components that must be methodologically deployed to achieve the stated purpose. Figure 3 shows a guide risk assessment model that is fit for this purpose. The identified risks are classified using a coded matrix according to the potential severity and likelihood of occurrence.

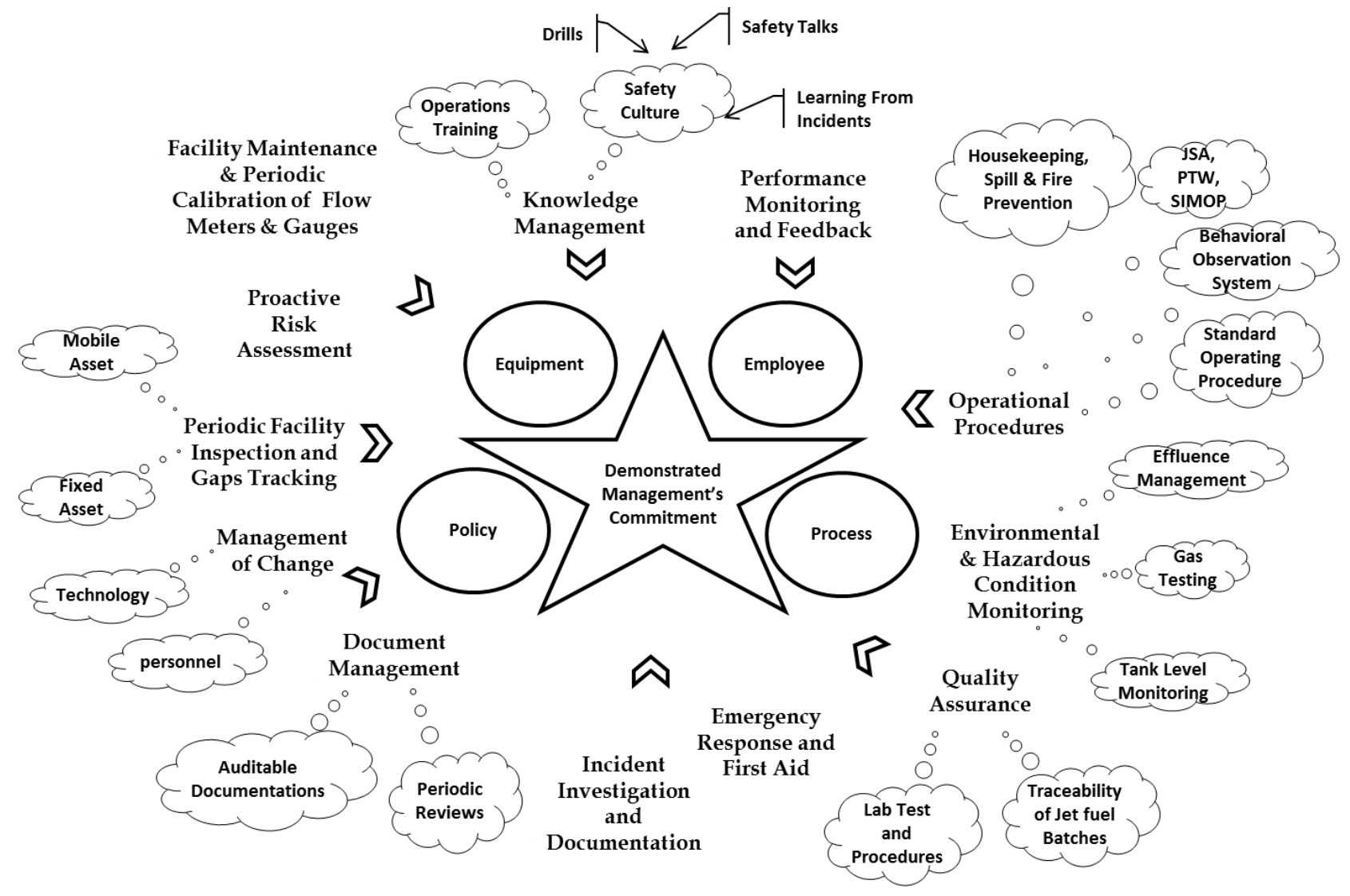

Figure 2. Components of ISQMS for Jet Fuel Supply Chain Management 


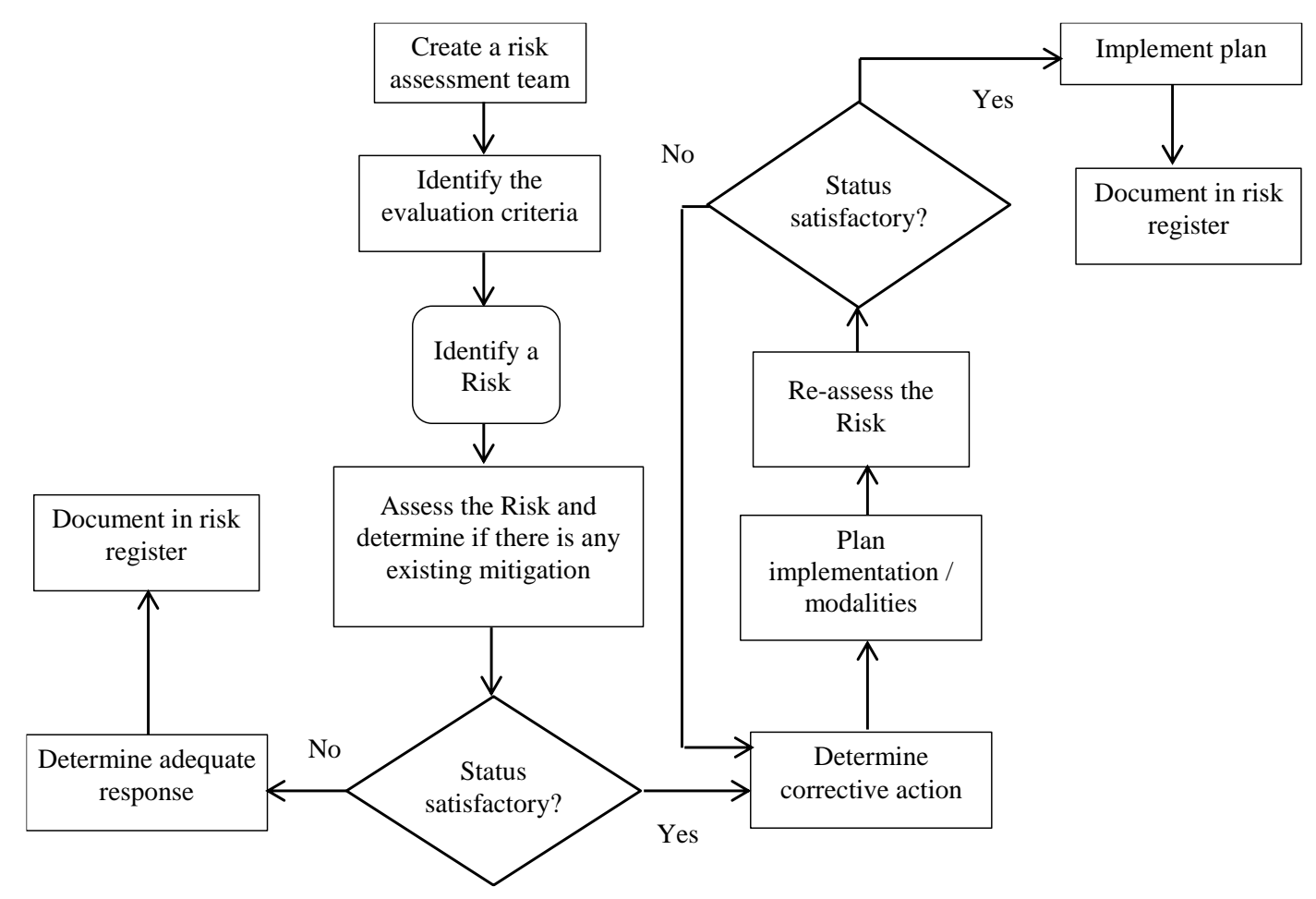

Figure 3. Risk assessment model [22]

\section{SMS and QMS implementations at various levels in the Value Chain}

\section{A. ISQMS at Jet Fuel Depot}

Process plants are typically at risk due to the various chemicals handled. In aviation, dynamic risk assessment and control theories can be applied towards accident prevention [23, 24]. Ensuring the safety of people and process at all times in an aviation, fuel depot is achieved by putting in place structures and systems to prevent errors and to ensure compliance with regulations and procedures at all times. Jet fuel handling and storage are the two key operations performed by the jet fuel depot. These activities may result in fuel grade mix up and other forms of contamination which will result in fuel degradation [11]. Likewise, personnel may be exposed to high level of jet fuel fumes and may have excessive skin contact with the jet fuel. Inhalation may result in respiratory tract irritation, sore throat and chronic inflammatory reaction of the lungs, and it can also affect the central nervous system inducing headache and dizziness. Contact with jet fuel may lead to eye, gut or skin irritation, and if a significant quantity is ingested, it may trigger nausea, vomiting and stomach distress [25]. Other associated health risks are detailed in the Material Safety Data Sheet for Jet A-1 Fuel. The ISQMS features at this stage include, but are not limited to the following:

- Quality Checks and Records- Standard quality test must be performed using the right equipment and procedures on each batch of fuel [5]. The results of such test must be documented and must be within acceptable limits. Traceability documentation is mandatory for aviation fuel depots particular because of its relevance in aircraft accident investigations. Records must be detailed enough with relevant certificates to allow for tracking any batch of fuel used for refuelling an aircraft, from the airfield depot through intermediate shore depots back to the refinery.

- Process flow diagrams-Personnel must be trained on the reading and interpretation of process diagrams to aid smooth and safe work flow

- Filtration Systems- Bi-filtration systems are deployed to remove contaminants both when loading and when discharging jet fuel from storage facilities.

- Daily tank draining to remove undissolved water thereby inhibiting microbial growth

- Standard Operating Procedure (SOP) - All major operational activities such as tank or mobile 
refueller loading and discharging operations must have a brief and easy to understand SOP clearly displayed at the operational area as a visual aid towards preventing errors and accidents.

- Facility Access Control to prevent unwanted intrusion and sabotage

- Job Control (JSA/PTW/SIMOP) - Job safety Analysis is a vital pre-task activity for identifying hazards, to ascertain how safe it is to perform the task, and to identify necessary controls to make the job safe. Permit To Work system and Simultaneous Operations management are also some of the job control tools deployed.

- Periodic Calibration- This is both for safety and for business reasons. It ensures that flow meters and gauges are accurate and that aircraft are not been over-fuelled which may affect aircraft weight and lift, and it also prevents the associated financial loss.

- Safety Drills- This increases the alertness of the personnel, and it helps in correcting wrong personnel behaviours

- Stock Inventory Management (SIM) - Aircraft run on schedules and a number of flights were grounded in the past due to fuel issues. SIM ensures that the fuelling company is aware of its accurate stock level and can notify an airline early of any fuel supply interruptions so that the airline can seek alternatives on time. It also help in preventing desperation on the part of the fuel supplier to meet a fuel supply schedule, in order to prevent contract breach or any associated penalties which may motivate the supply of any available off spec, low quality aviation fuel. Jet fuel availability and supply is a major challenge in some African countries.

- Facility Audit and Inspection- Both internal (selfregulatory) and external audits (local and international) are periodically carried out by airlines, IATA and various national regulatory bodies on aviation fuel depots to confirm and ensure compliance with industry regulations and to recommend closure plans for any gaps identified.

- Safety Days-This is one of the ways management shows their commitment to ISQMS. Apart from various safety refresher trainings, safety days are occasions for celebrating safety achievements; for some companies it incorporates lectures, awards and gifts for safety excellence and various merriments may be attached.

B. SMS and QMS in into plane operations
Aircraft are fuelled at the tarmac or apron, by welltrained personnel who must possess all relevant certifications and experience for the job. Fuelling mishaps have led to fuelling trucks catching fire, aircraft getting damaged and even burning on the tarmac in the past $[25,26]$.The ISQMS activities related to tarmac operations include the following:

- Quality Checks and Records [11]

- Bowser or Refueller Status Audit- Daily and other periodic checks are carried out on the bowsers using approved guidelines and checks

- Safety Systems Review- Safety systems on the bowsers such as the dead-man switch, interlocks, extinguishers, etc. are periodically subjected to functionality tests to prevent sudden failure while loading. Improvements and upgrade retrofits may be recommended.

- Tarmac Operators Performance and Concerns Reviews- This is to ensure that the workforce is adequately motivated to deliver top-notch quality and safe service. Apron personnel are a major interphase between the fuelling company and the airlines, and impressions formed by the airline based on their actions can make or mar business.

- Into-plane Procedure Compliance ChecksManagement team and safety personnel carry out impromptu field inspections to the apron to observe practices and compliance with operations guidelines

- Customer Satisfaction Assurance ProcessFeedback channels are created for airlines to give comments on their satisfaction and or concerns on service, quality and safety.

- Benchmark with Global Best Practices- The technical team stays abreast of developments, technological innovations, regulations reviews and global best practices so as to initiate necessary steps for management to consider such developments for implementation where applicable.

- Defensive driving trainings for bowser drivers

\section{SMS and QMS features on Hydrant System}

In hydrant systems, fuel is transferred from the airfield depots via pipes usually buried and connected to each hydrant pit at the apron. To fuel an aircraft, the hydrant dispenser is connected to the hydrant point and the fuelling nozzle on the dispenser is then connected to the aircraft's fuel loading valve. The ISQMS features at this stage include the following: 
- Safety Equipment and Features

$\checkmark$ Emergency Fuel Shutdown System (EFSS)

$\checkmark$ Pilot device - Operated via lanyard for immediately stopping the flow of jet fuel when suddenly pulled

$\checkmark$ System depressurising valve

$\checkmark$ Power Take Off (PTO) Mechanism

$\checkmark$ Inhibiting device

$\checkmark$ Hydraulic system pressure gauge

$\checkmark$ Pressure pulse alleviators

$\checkmark$ Float switch

$\checkmark$ Isolation Valves

- PLC based control

- Standard Operating Procedures

- Ready to go Emergency Response Team

- Trainings for personnel

\section{Compliance with regulations}

The aircraft fuelling contracts are highly competitive and global in nature. International platforms exist where airlines annually make offer on a proposed fuelling arrangement for different regions of the world, and interested into-plane (fuelling) companies in the respective countries would quote for these contracts. The process takes several stages, and usually, a primary and secondary supplier will be selected together with other ad hoc suppliers

with whom a contract will not exist, but may be contacted if the primary and secondary suppliers fail. This is a competitive process and the profile of each company in terms of safety, quality and performance history, membership of technical associations and technical partnerships determines their chances of winning the bids.

A way of demonstrating compliance with industry regulations and global best practices is by joining relevant regulatory and advisory bodies, some of these memberships are mandatory while others are voluntary. The aviation fuel regulators include the following IATA, Joint Inspection Group (JIG), National Civil Aviation Authorities, Petroleum Sector Regulators, Federal and State Airport Authorities, Oil Spill Detection and Management Agencies, ISO, various Technical Partnerships, etc.

Technical partnerships and membership of relevant bodies are based on meeting certain conditions and criteria. These operational, safety and quality requirements help in ensuring that aviation companies set up the best system and processes. Periodic audits are also carried out to track, measure compliance and assess operation license worthiness.

\section{The ISQMS Assurance Tools}

Achieving the goals of SMS and QMS requires that management collects data periodically, tracks and measures performance to enable appropriate interventions and policy reviews for correcting undesirable trends. A data driven management is equipped with vital information for assessing the effectiveness of various aspects of the SMS and QMS. Management needs to be assured that ISQMS is delivering its objectives so that the benefits of SMS and QMS could be fully realized. Assurance tools are deployed to guide the ISQMS process and these includes

- Safety policies, programs and procedure manuals

- Safety training, orientation and awareness measurement

- Safety and quality data collection, processing and measurement - According to ISO 31000, performance monitoring of safety systems is very vital, through the use of leading and lagging indicators [10]. Safety statistics from processed safety data should be made available to all employees. This develops an understanding of the current status and the need to either maintain the excellent status quo if already achieved, or push for excellence in their daily assignments

- Safety meetings

- Safety inspections and system audits

- Proactive risk assessment and management

- Safety incidents reporting and investigation

- Safety standards and handbooks

- Into-plane procedure compliance checks

- Tracking of maintenance of safety and quality equipment

- Emergency Response Plan (ERP) for various accident scenarios

- Trained Emergency Response Team (ERT) with adequate role definitions

- Safety and quality promotion activities

SMS and QMS stimulates workers' sense of accountability, and it promotes safe behaviour by employees which helps in reducing accident rate, and this can be further reinforced by deploying incentives [27]. Training is a major component of SMS and QMS which ensures that employees are adequately equipped with the needed knowledge [28] to safely perform their duties using the right procedures and tools. This reduces incidents and improves 
productivity due to the enhanced staff capability as a result of training.

Achieving the best of safety at work demands the commitment and contribution of all stakeholders; both management and employees must exhibit keen interest, competence and zeal. A safe place of work with quality product output is achieved by deploying safety and quality action pillars which helps in setting up the right culture and values.

The following are fundamentals to achieving ISQMS

- A clearly articulated vision of zero incidents and zero jet fuel contamination

- Compliance with corporate safety and quality policy

- Clear definition of staff responsibilities within the organization

- Standards and guidelines for key operational activities

- A leadership style that allows employees to express their concerns and views

- Comprehensive staff training

- The ISQMS Knowledge management System $[29,30]$, is delivered via the organizations' intranet to provide guidelines that will help employees to comply with SMS and QMS programs.

The supply of dry, quality, on-spec jet-A1 for aviation purposes eliminates fuel quality associated flight risks. Likewise, creating a safe work place, system of work and work conditions ensures that employees can go home to their families at the end of the work day in good health of mind and body. These are the ultimate goals of the ISQMS, and according to [31], the benefits of SMS can be direct (workers safety) and indirect e.g. loss minimization, avoidance of accident related litigations, benefits to contractors, insurers, etc. Accidents create concerns and attract intense regulatory scrutiny which puts management and employees under intense pressure. Through the ISQMS a continuously safe workplace and quality products can be assured.

\section{Conclusion}

It is no longer news that safety is a daily industrial requirement, but there are continuous efforts at developing methodologies and systems that will assure adequate and efficient management and implementation of safety. This study critically analysed the safety and quality management systems termed ISQMS, in the jet fuel supply chain which ensure that jet fuel is contamination free as it moves form one point to another, and also guarantee the safety of workers handling the process and the integrity of the work process. The ISQMS is a deliberate and conscious effort deployed to control operational risks, prevent hazards and unwanted events at work. It ensures safe-for-travel jet fuel quality, and it also provides opportunity to learn from the past.

\section{References}

[1] Badmus I., Fagbenle R. O., Oyewola O. M., Fuel-mix and energy utilization analysis of port harcourt refining company, Nigeria, Energy Science and Engineering, 1, (2013), 99-108.

[2] Wen-Kuei L., Risk assessment modeling in aviation safety management, Journal of Air Transport Management, 12, (2006). 267-273.

[3] Drees L., Mueller M., Schmidt-Moll C., Gontar P., Zwirglmaier K., Wang C., Risk analysis of the EASA minimum fuel requirements considering the ACARE-defined safety target, Journal of Air Transport Management, 65, (2017), 1-10.

[4] Ayra E. S., Insua D. R., Cano J., To fuel or not to fuel? Is that the question?, Journal of the American Statistical Association, 109, (2014), 465-476.

[5] Adekitan A. I., Shomefun T., John T. M., Adetokun B., Aligbe A., Dataset on statistical analysis of jet A-1 fuel laboratory properties for on-spec into-plane operations, Data in Brief, 19, (2018), 826-834.

[6] Herrero S. G. a., Saldaña M. A. M., del Campo M. A. M., Ritzel D. O., From the traditional concept of safety management to safety integrated with quality, Elsevier, (2002)

[7] Hamidi N., Omidvari M., Meftahi M., The effect of integrated management system on safety and productivity indices: Case study; Iranian cement industries, Safety Science, 50, (2012), 180-1189.

[8] Aneziris O. N., Nivolianitou Z., Konstandinidou M., Mavridis G., Plot E., A Total Safety Management framework in case of a major hazards plant producing pesticides, Safety Science, 100, (2017), 183-194.

[9] Popova L. F., Yashina M. N., Bocharova S. V., Cherkashnev R. Y., Development of methodology of identification of the quality management system processes, Quality - Access to Success, 19, (2018), 43-47. 
[10] Kontogiannis T., Leva M. C., Balfe N., Total Safety Management: Principles, processes and methods, Safety Science, 100, (2017), 128-142.

[11] Adekitan A. I., Safeguards: A key process safety tool in jet fuel management from refinery to aircraft wings, Process Safety Progress, 2018.

[12] Yiu N., Sze N. N., Chan D., Implementation of safety management systems in Hong Kong construction industry - A safety practitioner's perspective, Journal of Safety Research, 64, (2018), 1-9.

[13] Carnino A., Management of safety, safety culture and self-assessment, Apostilha do Curso Básico de Treinamento profissional em segurança Nuclear da Agência Internacional de Energia Atômica, Instituto Militar de Engenharia, Rio de Janeiro, 2002.

[14] Pappas S., Comprehensive Safety - Just Another Paperwork Drill?, Opflow, 24, (1998), 10-11.

[15] Frazier C. B., Ludwig T. D., Whitaker B., Roberts D. S., A hierarchical factor analysis of a safety culture survey, Journal of Safety Research, 45, (2013), 15-28.

[16] Chen W., Li J., Safety performance monitoring and measurement of civil aviation unit, Journal of Air Transport Management, 57, (2016), 228233.

[17] Liou J. J. H., Tzeng G.H., Chang H.C., Airline safety measurement using a hybrid model, Journal of Air Transport Management, 13, (2007), 243-249.

[18] Kines P., Andersen D., Andersen L. P., Nielsen K., Pedersen L., Improving safety in small enterprises through an integrated safety management intervention, Journal of Safety Research, 44, (2013), 87-95.

[19] Chistokletov N., Vavilin Y., Safety management system of machine-building production, Engineering Review, 38, (2018.) 226-231.

[20] Fernández-Muñiz B., Montes-Peón J. M., Vázquez-Ordás C. J., Relation between occupational safety management and firm performance, Safety Science, 47, (2009), 980991.
[21] Zohar D. Safety Climate in Industrial Organizations, Theoretical and Applied Implications, 65, 1980.

[22] Adekitan A., Root Cause Analysis of a Jet Fuel Tanker Accident, International Journal of Applied Engineering Research, 12, (2017), 14974-14983.

[23] Favarò F. M., Saleh J. H., Application of temporal logic for safety supervisory control and model-based hazard monitoring, Reliability Engineering \& System Safety, 169, (2018.) 166178.

[24] Adekitan A. I., Risk assessment and safety analysis for a jet fuel tank corrosion recertification operation, International Journal of Mechanical Engineering and Technology, 9, (2018), 387-396.

[25] Fewtrell P., Petrie A., Lines I., Cowell N., Livingston A., Jones C., Quantified Risk Assessment of Aircraft Fuelling Operations, The Health and Safety Executive, 2000.

[26] B. Schlappig, Uh Oh: Etihad A380 Refueling Truck Fire In Abu Dhabi, (2016). Available: http://onemileatatime.boardingarea.com/2016/0 2/19/etihad-a380-fire/

[27] Ian D., Stephen Y., Managing safety: an attitudinal-based approach to improving safety in organizations, Leadership \& Organization Development Journal, 17, (1996), 13-20.

[28] Jensen A., Aven T., A new definition of complexity in a risk analysis setting, Reliability Engineering \& System Safety, 171, (2018), 169173.

[29] Podgórski D., The Use of Tacit Knowledge in Occupational Safety and Health Management Systems, International Journal of Occupational Safety and Ergonomics, 16, (2010), 283-310.

[30] Sherehiy B., Karwowski W., Knowledge management for occupational safety, Health and ergonomics, 16, 2006.

[31] Mossink J., de Greef M., Inventory of socioeconomic costs of work accidents, Office for Official Publications of the European Communities, 2002. 